\title{
Approaches and Recent Advances in Protein and Peptide Drug Delivery System
}

\author{
SAIMA NAZ ${ }^{1 *}$, SABA SAEED ${ }^{2}$, MAVRA IRFAN ${ }^{3}$, AHMAD MANAN MUSTAFA CHATHA ${ }^{4}$, SUMMAN IQBAL ${ }^{5}$, JAWERIA \\ FAROOQ ${ }^{6}$, ZONAIRA AKHTAR ${ }^{7}$, UJALA SAMI ${ }^{8}$ \\ ${ }^{*}, 5,6,7,8$ Government Sadiq College Women University, Bahawalpur, Pakistan. \\ ${ }^{2,3}$ Department of Zoology, University of the Punjab, Lahore, Pakistan. \\ ${ }^{4}$ Department of Entomology, University College of Agriculture and Environmental Sciences, The Islamia University of Bahawalpur, Pakistan. \\ Correspondence to Saima Naz Email: saima.naz@gscwu.edu.pk, Cell: 03346606748
}

\begin{abstract}
Peptide and protein drug are commercially available as therapeutics and are prepared by various biotechnology processes.As they lack drug stability during their delivery, so protein structures are modified to maintain pharmaceutical properties of proteins. Various approaches for delivery of protein and peptide drugs are used for proper formulation of drugs. In addition, various advancements in protein and peptide drug delivery have try to overcome the issues during delivery of these therapeutics like increased stability, low toxicity level and increased resistance to proteolytic inactivation, bioavailability, efficiency and improve circulation period. There is a need to develop multifunctional drugdelivery systems and advance technologies that allow production of high quality products at affordable cost. The study was conducted to check various approaches and recent advances in protein/peptide drug delivery system to improve patient compliance when compared with conventionalmethods for drug delivery.
\end{abstract}

Keywords: Protein and peptide, drug delivery system, microspheres, liposomes, nanoparticles, PE Gylation.

\section{INTRODUCTION}

In recent decades, biotechnological advances are important for discovery of various protein and peptide drugs and enable their production on large scale. Major advances in enhancing therapeutic bioavailability at site-specific delivery involve the quest of new drug delivery approaches and new modes of action mainly including multidisciplinary scientific approach (Haag and Kratz, 2006;Semete et al., 2010). Such approaches solve the problems of drug solubility, $\mathrm{pH}$ changes, low bioavailability, limited routes of administration and protect drug from photo degradation and enhance the control release of drugs (Korting and SchaferKorting, 2010;Wang et al., 2011). Therefore the treatment of various diseases like cancer or other infectious diseases allocates new tasks for pharmaceutical technology for the identification of novel drug candidates. A lot of attention is being paid on the effect of shape of particulate materials on the physiological mechanisms (Daum et al.,2012).

Delivery of the drug is the process that involves pharmaceutical compounds administration for achieving a therapeutic effect in humans and animals. Different methods have been vigorously encouraged for the delivering the drug at the controlled rate along with slow delivery at the targeted area. Various drug delivery methods have been formulated that are being investigated for pulmonary and nasal delivery. These approaches include proliposomes, liposomes, gels, microspheres, prodrugs and many others. The most significant approach that has gained a lot of interest recently is nanoparticles. These biodegradable polymers fulfill the significant requirements of delivery system such as they can be transferred into aerosols during aerosolization. They can target specific areas in the lungs along with controlled release of drug in predetermined way. Finally they can be degraded within particular period of time (Tiwari et al., 2012).
Further researches have revealed issues regarding the use of recombinantly expressed therapeutic proteins in protein drug delivery system which mainly involves problems like stability during long term storage and delivery efficacy to avoid harsh immunogenic side effects. Therefore controlled chemical modifications have been done to fulfill the solutions of drug delivery system mainly involving substitutions, PEGylation and acylation. Formulations based on lipids and hydrogels have been developed into generic delivery systems (Frokjaer and Otzen, 2005).

The field of drug delivery involves open loop system that is also known as externally regulated system and closed loop systems being self regulated. The external triggers applied though externally controlled devices for pulsed delivery include ultrasound, thermal, magnetic and electric triggers. The closed loop system work without external intervention and utilize approaches like $\mathrm{pH}$ sensitive polymers, $\mathrm{pH}$-sensitive drug solubility, enzymesubstrate reactions and metal concentration dependent hydrolysis (Kost and Langer, 2012).

Nowadays the struggle to produce new drug carrier systems is mostly high. These approaches serve as a hope to treat various infectious diseases. Various technologies and innovations have been made in clinical studies and help in marketing of the products with favorable results. Recent advances may include versatility of polymers like poly (D-L-lactic-co-glycolic) (PLGA) as new dosage form that avoid hindrances in targeting strategies. Furthermore the main focus of delivery system involves the microenvironment of cells and their interaction with dosage forms. However, we can assume that there are still many areas in this field that face many challenges. An insight into the major smart delivery system reveals that they might work well in vitro but may fail in complicated in vivo environment. But still further advancements will be made in the future with the development of new entities that will be available and will act as clever polymers for the treatment 
of diseases (Martinho et al., 2011;Zhang et al., 2013).The present study focus onvarious approaches and advances in protein and peptide drug delivery system that might improve patient compliance.

Approaches for drug delivery system: The protein and peptides have following approaches according to different routes.

Chemical alteration: Chemical alterations include olefenic replacement, removal of carboxyl group from dehydroamino acid. It results in more stable drug and helps in improving half-life of plasma and increase the stability of enzyme (Jani et al., 2012; Savale, 2016). Chemical targeting involves the alteration of surface of particles through molecular recognition units that respond to disease environments. This can be done through identification of lead structures that are specific for each target (Morachis et al., 2012;Bhardwaj et al., 2014)

Alpha amino acid substitution: Amino acid substitution include substitution of the D and L- amino acid changes the physiological properties of protein transport system (Lalatsa et al., 2012). Peptides and proteins have extensive medicinal characteristics but membrane impermeability and rapid proteolysis limits their activity. Therefore naturally occurring peptides are edited for greater stability in drug delivery system. Naturally occurring aminoacids appear in L-amino acid configuration. The metabolic stability of biologically active peptides can be increased through incorporation of D-amino acids (Melchionna et al., 2016; Qvit et al., 2017).

Nobex Conjugated Technology: It involves amphiphilic protein conjugation. In this the amino group of proteins is attached to alkyl group along with a chain of polyethylene glycol (Hamman et al.,2005). Nobex conjugated technology has been used in oral drug delivery where protein, peptides and small organic molecules are modified through amphiphilic protein conjugate having short chain PEG and alkyl groups attached to amino groups of protein molecule. This technique provides stability to enzymatic degradation and enhanced solubility for optimized formulation. This technology has been successfully used in the development of oral conjugated insulin with improved solubility and effectiveness by adding short chain PEC and alkyl group to Lys-29 (Gordon Still, 2002; Semalty et al., 2007).

\section{Enhancers}

Enhancers act as carrier system because of greater proteins size and act as wetting agents or bile salts for oral drug delivery (Whitehead et al., 2008). Bile salts act as surface active agents and chelating, hence increases the nasal absorption of proteins and peptide. Enhancers such as monosaturated fatty acid, Hexadeuterodimethyl sulfoxide, wetting agents and cycloheptanone have been are important in transderml delivery (Ghori et al., 2015). Penetration enhancers cause plasma membrane fluidization, protease inhibition and are important in loosening of tight junctions between cells followed by enhanced thermodynamic activity of the proteins. Permeation enhancers cause the penetration of drugs into transdermal therapeutic system hence playing an important role of drug delivery through skin and thus decrease barrier resistance. Compounds having enhancer abilities include azones and sulfoxides, alkanols, alcohol, surfactants and glycols (Williams and Barry 2012; Patil and Saraogi 2014).

\section{Protease inhibitors}

Protease inhibitors are co-administrated with peptides and proteins to providing an environment for maximum enzyme stability. The stability of insulin is shown through inhibitors like aprotinin (Maeda et al., 2013). These inhibitors are used in preventing the proteolysis of the proteins and peptides. The choice of the protease inhibitors depends upon the degrading properties of the peptide or protein to reach the target area while crossing mucosal epithelial layer. Such carriers are important in treatment of infectious diseases, degenerative diseases and cancer. Captopril an inhibitor of ACE has been used in treatment of CVD for a long time (Semalty et al., 2007; Drag and Salvesen, 2010).

\section{Viscosity Modification}

Viscosity modification involves increasing half time of clearance by using higher viscosity medium (Hoare and Kohane, 2008). Viscoelastic flow properties are exhibited by dermal drug delivery vehicles for enhancing patient compliance. Generally high viscosity is preferable for types of formulations that require manual application. For this purpose gelling agents have been added to dermal pharmaceuticals that lead to enhanced skin permeation. This provides a prolonged time for drug diffusion across the skin (Binder et al., 2019).

\section{4. pH Modification}

The solubility of protein and peptide DDS is increased by $\mathrm{pH}$ modification away from isoelectric point as their solubility is low at isoelectric point (Schmaljohann, 2006). Recently $\mathrm{pH}$ sensitive drug delivery has led to beneficial results in patient therapeutic efficiency as such system release drug at particular time as per pathophysiological need of the disease and $\mathrm{pH}$ of fluids of gastrointestinal tract (GIT) provide media for drug delivery. The charge density of drug polymer depends upon the ionic concentration and $\mathrm{pH}$ of environmental solution. If the $\mathrm{pH}$ of solution is altered, then swelling and deswelling of drug polymer may occur. Commonly used $\mathrm{pH}$ sensitive polymers are derivatives of acyclic acid and cellulose (Balamuralidhara et al., 2011).

\section{Phonophoresis and lontophoresis}

Phonophoresis involves the control release of drug from a contact agent through the skin under the influence of ultrasonic waves. Ultrasonic waves cause the enhanced penetration of drug through mechanical, thermal and chemical change of biological tissues and thermal energy released during mechanical disturbance mediate phonophoretic drug delivery. While iontophoresis technique facilitates the movement of ions across membrane through generation of electrical potential gradient. The transdermal delivery system includes this noninvasive method for local and systemic delivery of proteins and peptides. Hyperhidrosis is successfully treated through iontophoresis. (Jani et al., 2012).

Phonophoresis technique is more effective as compared to iontophoresis as ultrasonic waves penetrate $5 \mathrm{~cm}$ below the skin whereas the latter only travels $1 \mathrm{~cm}$ deep in the skin. The time of treatment for iontophoresis ranges between 20 to 30 minutes whereas Phonophoresis takes only 10 minutes. Iontophoresis requires the ionization of drug before use (Machet and Boucaud, 2002). 


\section{Formulation vehicle approaches}

Approaches of Protein and Peptides can be successfully obtained by using various carrier systems which are following.

a) Emulsions

Emulsions constitute heterogeneous systems containing two immiscible liquids where fine droplets are uniformly dispersed over other liquid phase through mechanical agitation process. These are designed for dermatological products which facilitate the penetration of drugs into the skin. Most extensively designed emulsions include solidwater-in-oil (S/W/O) and solid-oil-in-water (S/O/W) emulsions that deliver the drug efficiently to the skin (Lu and Gao, 2010).

Emulsions help in protection of drugs from various chemicals as acids and luminal proteases in the GIT and increases permeability in the intestinal mucosa. It is an important application in DDS which inhibit instabilities and help in long term storage of drugs (Jani et al., 2012; Savale, 2016).

b) Microspheres

The uniform distribution of drug in oral drug delivery of protein/ peptides drugs are known as microspheres (Savale, 2016).These are small size spherical particles comprising dispersed drug either in solution/ microcrystalline from (Muralidhar et al., 2017). Different biodegrading polymers are used in microspheres and are employed for delivery of micro-molecules, macro-molecules and proteins. These microspheres have ability to release drug for 1-3 months into animals after intramuscular/ subcutaneous inoculation (Jani et al., 2012). Leuprolide microspheres comprising LHRH super-agonist leuprorelin acetate along with polylactic-coglycolic acid and polylactic acid. Enzyme replacement therapeutics using prolidase micro-particulate method have been organized by PLGA polymer. PLGA microspheres having protein/ peptide drugs are glycoprotein (GP) Ilb/llla antagonist, interleukin-1 $\alpha$ and plasmid DNA (Genta et al., 2001; Diez and de Ilarduya, 2006).Microspheres are $\mathrm{pH}$ sensitive and help in stopping proteolysis in stomach and small intestine. They are physically and chemically more stable than liposomes and act as important vehicle for proteins DDS in pulmonary delivery (Cook et al., 2005).

\section{c) Liposomes}

Liposomes (phospholipid-based vesicles) are colloidal carriers in drug delivery system that utilizes biodegradable material in which various bilayer lipids entrap aqueous media. Lipophilic drugs such as steroids, antimicrobial drugs and vaccines are commonly encapsulated in liposome. Recently long circulating liposomes (LCL) and highly interactive cationic liposomes have gained important role in drug delivery system(Sihorkar and Vyas, 2001; Arias, 2013).Pulmonary absorption is facilitated by insulin and cyclosporin liposomal formulation (Cook et al., 2005; Samad et al., 2007).

\section{d) Nanoparticles}

Solid lipids nanoparticles promote drug delivery efficiently through dermal, ocular, rectal and pulmonary routes and provides greater drug stability and protection along with its controlled release. Polymeric nanoparticles (PNP) utilize the drug release through nanoparticles erosion or diffusion at targeted area. Such drug carriers are made through encapsulation of drug on PNP surface during polymerization reaction. The porous structure and high biocompatibility of silica nanoparticles exhibit various advantages in drug delivery system. Magnetic nanoparticles use external magnetic field for controlled release of drug and is significant in cancer therapy (Arruebo et al., 2007; Wilczewska et al., 2012). The vehicles for oral drug delivery are nanoparticles. Nanoparticles carrying peptides prevent the peptides from enzyme degeneration and improve assimilation in intestine (Italia et al., 2011).

\section{e) Microparticles based lipids}

In 1990 solid lipid particles were introduced as an alternative drug delivery system to liposomes and emulsions. These carriers constitute a hydrophobic core that is solid at body temperature and is stabilized by surfactant layer encapsulated in their surface. Such particles have good biodegradability and have a significant role in inhalation therapy as well as target respiratory diseases. The drugs released in such sustained manner are absorbed efficiently and yield extended medicinal effects (Scalia et al., 2015; Ngan and Asmawi, 2018).Such microparticles are also called as pulmospheres; carry human immunoglobulin $(\mathrm{lgG})$ to the respiratory tract of mice, which activates immune reactions. It is used in pulmonary drug delivery (Cook et al., 2005).

\section{Recent advances in protein peptide drug delivery} system

Biotechnology advancement has led to the production of proteins and peptides drug systems economically. Following are advances in protein peptide drug delivery system.

\section{Macroflux transdermal technology}

Macroflux transdermal patch technology carries drugs along with proteins and peptides in a controlled fashion that brings comfort to the patient with efficiency. It integrates titanium micro projection and fixes it to a polymeric adhesive back. Micro capillaries absorb this drug for systemic distribution (Matriano et al., 2002; Kumar and Philip, 2007; Kumar et al., 2007; Gupta and Sharma, 2014.).

\section{Xenoport's transcytosis}

It is a wonderful technology which brings about receptor-mediated transcytosis. Such transcytosis combine the targeted ligand to protein drugs. Such ligands when united with peptide drugs help the permeability of drugs in the intestine and improve incorporation (Kumar et al., 2007).

\section{PEGylation}

According to recent advancement, PEGylation is important in peptide DDS. It attaches polymer PEG to specific peptides fragments that enhance the efficiency of many therapeutic macromolecules. It modifies the proteins and peptides, antibody fragments and oligonucleotides (Savale, 2016). PEGylation of nanoparticles is a widespread technique that upsurges blood passage and retaining time, drops prompt clearance along with nonspecific interfaces using serum proteins (Pelaz et al., 2015; Mukherjee et al., 2020). PEG provide more stability for drug transfer and improved circulation period (Liu et al., 2016). 


\section{Depo-Foam technology}

A variety of categories of liposomal formulations have been developed as drug delivery carriers for control release of proteins and peptides. This technology can load high amount of drug with a higher recovery along with encapsulation efficiency (Bari, 2010). Injectable drugs are substituted for persistent drug release formulation; employed for smaller/ larger molecules (Mitragotri et al., 2014).

\section{Polymeric micelles}

Polymeric micelles act as colloidal vehicle for drugs that are less soluble and are amphiphatic. They have more steadiness than the micelles that act as surfactants and have ability to dissolve amphiphatic compounds. This hydrophobic shell and small size show extended distribution time inside the body (Nasongkla et al., 2006). Copolymer micelles contain cation fragment and water loving segment which combine amid polyanionic DNA which lead to formation of block copolymer micelles. The polyion DNA and cation segment are covered with water loving coating of polymer. This structure shows an elevated suspension constancy and less contact with blood (Gaucher et al., 2005). Polymeric vesicles having developing stage for drug delivery; they have notable facts as drug nanocarriers (Ke et al., 2018; Padmavathy et al., 2018; Yang et al., 2018; Zheng et al., 2018). Either hydrophilicity or hydrophobicity of block copolymers might be improved, ensuing disassociation of polymeric micelles/ vesicles (Johnson and Preman, 2019; Lei et al., 2020).

\section{Rod-type covered technique for peptides}

Protein drugs release requires a novel technique uses silicon that is converted to rod type shape. Preparation of such formulation is done under mild conditions with no use of heat or organic solvents. It facilitates accurate discharge of the protein medicine and boosts up the efficiency of drug and lowers the regularity of dosage and its toxic effects (Kumar and Philip, 2007). Rod-like insertion allow embedding into holes by micro-fracture therapy and not only improve this surgery but also helpful as drug formulation (Shim et al., 2008).

\section{Microneedles}

Microneedles are an unproblematic technology for delivery of drugs into skin and improve bioavailability, and efficiency. It may not bring distress or infection likened with old needle stick wounds, permitting patient's amenability to cure (Queiroz, et al., 2020). Such microneedles have ability to transport proteins and peptides in addition to vaccines, insulin, growth hormones etc. and are currently used for biosensors, fluid sampler and micro-analysis (Chen et al., 2017; Yu et al., 2017; Zhao et al., 2017; Yin et al., 2018; Ali et al., 2020). Powder carrying microneedles are more appreciated compared with dissolving microneedles because of its validity to various powder therapeutics (Kim et al., 2020).

\section{Other latest developments}

Techniques such as Aradigm-AERx pulmonary technology facilitate carrying chemicals such as opiate and insulin to the lungs. Other technique called as inhalation technology (AIR) facilitates efficient delivery of powder form of protein components deep into the lungs. NKTR helps patients with type-I diabetes to inhale insulin Exubera. Several other technologies have been developed for the accurate delivery of drugs (Kumar and Philip, 2007). Various methods relating to incorporation of drug into proteinpeptide drug delivery system are described below (Table 1).

\section{CONCLUSION}

Proteins represent an innovative class of the therapeutic agents showing new perceptions in the treatment of diseases. Modern pharmaceutical technology provide a proper design and formulation for novel drugs. Pharmacological and biotechnological study indicate that drug delivery systems built on several helpful applications. The actual and convincing act of peptides makes the pills of high-quality for the cure of plentiful infections. The success of the therapeutics is strongly influenced by the differential delivery of target antigen, the choice of targeting protein or peptide and drug release characteristics of the linker used. Despite much progress in bio-conjugation chemistry, the challenges of nanomedicine, the improvement of effective therapeutic formulations is still an uncompleted task. Further, there is a need of more advance technology for delivery of protein and peptide therapeutics that might improve their encapsulation efficiency, biodegradability biocompatibility of DDS, host toxicity, tissue specific action and are also cost effective.

\section{REFERENCES}

1. Haag, R. and Kratz, F., 2006. Polymer therapeutics: concepts and applications. Angewandte Chemie International Edition,45(8):1198-1215.

2. Semete, B., Booysen, L., Lemmer, Y., Kalombo, L., Katata, L., Verschoor, J. and Swai, H.S. 2010. In vivo evaluation of the biodistribution and safety of PLGA nanoparticles as drug delivery systems. Nanomedicine: Nanotechnology, Biology and Medicine,6(5):662-671.

3. Korting, H. C. and Schafer-Korting, M. 2010. "Carriers in the topical treatment of skin disease," In Drug delivery, Springer, pp. 435-468.

4. Wang, S., Tan, M., Zhong, Z., Chen, M. and Wang, Y. 2011. Nanotechnologies for curcumin: an ancient puzzler meets modern solutions. Journal of Nanomaterials, 2011.

5. Daum, N., Tscheka, C., Neumeyer, A., and Schneider, M. 2012. Novel approaches for drug delivery systems in nanomedicine: effects of particle design and shape. Wiley Interdisciplinary Reviews: Nanomedicine and Nanobiotechnology, 4(1):52-65.

6. Tiwari, G., Tiwari, R., Sriwastawa, B., Bhati, L., Pandey, S., Pandey, P., \& Bannerjee, S.K. 2012. Drug delivery systems: An updated review. International journal of pharmaceutical investigation,2(1):2.

7. Frokjaer, S. and Otzen, D.E. 2005. Protein drug stability: a formulation challenge. Nature reviews Drug discovery, 4(4):298-306.

8. Kost, J. and Langer, R. 2012. Responsive polymeric delivery systems. Advanced drug delivery reviews, 64:327-341.

9. Martinho, N., Damge, C., and Reis, C.P. 2011. Recent advances in drug delivery systems. Journal of biomaterials and nanobiotechnology,2(05):510. 
10. Zhang, Y., Chan, H.F. and Leong, K.W. 2013. Advanced materials and processing for drug delivery: the past and the future. Advanced drug delivery reviews,65(1):104-120.

11. Jani, P., Manseta, P. and Patel, S., 2012. Pharmaceutical approaches related to systemic delivery of protein and peptide drugs: an overview. Int J Pharm Sci Rev Res.,12(1): 42-52.

12. Savale, S.K., 2016. Protein and peptide drug delivery system. World J Pharm Sci, 5(4):2278 - 4357.

13. Morachis, J.M., Mahmoud, E.A., \& Almutairi, A., 2012. Physical and chemical strategies for therapeutic delivery by using polymeric nanoparticles. Pharmacological reviews, 64(3):505-519.

14. Bhardwaj, Y.R., Pareek, A., Jain, V. and Kishore, D., 2014. Chemical delivery systems and soft drugs: Retrometabolic approaches of drug design. Saudi Pharmaceutical Journal, 22(4): 290-302.

15. Lalatsa, A., Schatzlein, A.G., Mazza, M, Le, T.B.H. and Uchegbu, I.F., 2012. Amphiphilic Poly (I-Amino Acids) new materials for drug delivery. $J$ Control Release, 161(2): 523536.

16. Melchionna, M., Styan, E. and Marchesan, S., 2016. The unexpected advantages of using D-amino acids for peptide self-assembly into nanostructured hydrogels for medicine. Current topics in medicinal chemistry, 16(18): 2009-2018.

17. Qvit, N., Rubin, S.J., Urban, T.J., Mochly-Rosen, D. and Gross, E.R., 2017. Peptidomimetic therapeutics: scientific approaches and opportunities. Drug Discovery Today, 22(2): 454-462.

18. Hamman, J.H., Enslin, G.M. and Kotz, A.F., 2005. Oral delivery of peptide drugs. BioDrugs.,19(3): 165-177.

19. Gordon Still, J., 2002. Development of oral insulin: progress and current status. Diabetes/Metabolism Research and Reviews, 18(S1): S29-S37.

20. Semalty, A., Semalty, M., Singh, R., Saraf, S.K. and Saraf, S., 2007. Properties and formulation of oral drug delivery systems of protein and peptides. Indian Journal of Pharmaceutical Sciences, 69(6): 741.

21. Whitehead, K., Karr, N. and Mitragotri, S., 2008. Safe and effective permeation enhancers for oral drug delivery. Pharm Res.,25(8): 1782-1788.

22. Ghori, M.U., Mahdi, M.H., Smith, A.M. and Conway, B.R., 2015. Nasal drug delivery systems: An overview. Am. J. Sci., 3(5): 110-119.

23. Williams, A.C. and Barry, B.W., 2012. Penetration enhancers. Advanced drug delivery reviews, 64: 128-137.

24. Patil, U.K. and Saraogi, R., 2014. Natural products as potential drug permeation enhancer in transdermal drug delivery system. Archives of dermatological research, 306(5): 419-426.

25. Maeda, H., Nakamura, H. and Fang, J., 2013. The EPR effect for macromolecular drug delivery to solid tumors: improvement of tumor uptake, lowering of systemic toxicity, and distinct tumor imaging in vivo. Adv Drug Deliv Rev.,65(1): 71-79.

26. Semalty, A., Semalty, M., Singh, R., Saraf, S.K., \& Saraf, S., 2007. Properties and formulation of oral drug delivery systems of protein and peptides. Indian Journal of Pharmaceutical Sciences, 69(6): 741.
27. Drag, M. \& Salvesen, G.S., 2010. Emerging principles in protease-based drug discovery. Nature reviews Drug discovery, 9(9): 690-701.

28. Hoare, T.R. and Kohane, D.S., 2008. Hydrogels in drug delivery: Progress and challenges. Polymer (Guildf).,49(8): 1993-2007.

29. Binder, L., Mazál, J., Petz, R., Klang, V. and Valenta, C., 2019. The role of viscosity on skin penetration from cellulose ether based hydrogels. Skin Research and Technology, 25(5): 725-734.

30. Schmaljohann, D., 2006. Thermo-and ph-responsive polymers in drug delivery. Adv Drug Deliv Rev.,58(15): 16551670.

31. Balamuralidhara, V., Pramodkumar, T.M., Srujana, N., Venkatesh, M.P., Gupta, N.V., Krishna, K.L., \& Gangadharappa, H.V., 2011. pH sensitive drug delivery systems: A review. Am J Drug Discov Dev, 1(1): 25.

32. Machet, L. \& Boucaud, A. 2002. Phonophoresis: efficiency, mechanisms and skin tolerance. International journal of pharmaceutics, 243, (1-2) 1-15.

33. Lu, G. W. \& Gao, P., 2010, "Emulsions and micro emulsions for topical and transdermal drug delivery," In Handbook of non-invasive drug delivery systems, Elsevier, pp. 59-94.

34. Muralidhar, P., Babajan, S., Bhargav, E. and Sowmya, C., 2017. An Over View: Protien and Peptide Based Drug Delivery Int. J. Pharm. Sci. Rev. Res.,42(1): 169-178.

35. Genta, I., Perugini, P., Pavanetto, F., Maculotti, K., Modena, T., Casado, B., Lupi, A., ladarola, P. and Conti, B., 2001. Enzyme loaded biodegradable microspheres in vitro: ex vivo evaluation. J. of Controlled Release, 77(3): 287-295.

36. Díez, S. and de llarduya, C.T., 2006. Versatility of biodegradable poly ( $\mathrm{D}, \mathrm{L}$-lactic-co-glycolic acid) microspheres for plasmid DNA delivery. Euro. J. of Pharm. and Biopharm, 63(2): 188-197.

37. Cook, R.O., Pannu, R.K. and Kellaway, I.W., 2005. Novel sustained release microspheres for pulmonary drug delivery. J. Control Release.,104(1): 79-90.

38. Sihorkar, V. \& Vyas, S.P. 2001. Potential of polysaccharide anchored liposomes in drug delivery, targeting and immunization. J.Pharm.Pharm.Sci, 4, (2) 138-158.

39. Arias, J.L. 2013. Liposomes in drug delivery: a patent review (2007GÇôpresent). Expert opinion on therapeutic patents, 23, (11) 1399-1414.

40. Samad, A., Sultana, Y., Aqil, M., 2007. Liposomal drug delivery systems: an update review. Curr Drug Deliv.,4(4): 297-305.

41. Arruebo, M., Fernandez-Pacheco, R., Ibarra, M.R. and Santamara, J.S., 2007. Magnetic nanoparticles for drug delivery. Nano today, 2(3): 22-32.

42. Wilczewska, A.Z., Niemirowicz, K., Markiewicz, K.H. and Car, H., 2012. Nanoparticles as drug delivery systems. Pharmacological reports, 64 (5): 1020-1037.

43. Italia, J.L., Sharp, A., Carter, K.C., Warn, P. and Kumar, M.R., 2011. Peroral amphotericin B polymer nanoparticles lead to comparable or superior in vivo antifungal activity to that of intravenousambisome or fungizone. PLoS One.,6(10): 25744.

44. Scalia, S., Young, P.M. and Traini, D., 2015. Solid lipid microparticles as an approach to drug delivery. Expert opinion on drug delivery, 12(4): 583-599.

45. Ngan, C.L. and Asmawi, A.A., 2018. Lipid-based pulmonary delivery system: a review and future considerations of 
formulation strategies and limitations. Drug delivery and translational research, 8(5): 1527-1544.

46. Matriano, J.A., Cormier, M., Johnson, J., Young, W.A., Buttery, M., Nyam, K. and Daddona, P.E., 2002. Macroflux® microprojection array patch technology: a new and efficient approach for intracutaneous immunization. Pharmaceutical research, 19(1): 63-70.

47. Kumar, R. and Philip, A., 2007. Modified transdermal technologies: Breaking the barriers of drug permeation via the skin. Trop J Pharm Res.,6(1): 633-644.

48. Kumar, M.D., Baboota, S., Ahuja. A., Hasan. S. and Ali. J.. 2007. Recent advances in protein and peptide drug delivery systems. Curr Drug Deliv.,4(2):141-151.

49. Gupta, H. and Sharma, A., 2014. Recent trends in protein and peptide drug delivery systems. Asian Journal of Pharmaceutics (AJP): Free full text articles from Asian $J$. Pharm., 3(2).

50. Pelaz, B., del Pino, P., Maffre, P., Hartmann, R., Gallego, M., Rivera-Fernandez, S., de la Fuente, J.M., Nienhaus, G.U. and Parak, W.J., 2015. Surface functionalization of nanoparticles with polyethylene glycol: effects on protein adsorption and cellular uptake. ACS nano, 9(7): 6996-7008.

51. Mukherjee, S., Kotcherlakota, R., Haque, S., Bhattacharya, D., Kumar, J.M., Chakravarty, S. and Patra, C.R., 2020. Improved delivery of doxorubicin using rationally designed PEGylated platinum nanoparticles for the treatment of melanoma. Materials Science and Engineering: C, 108: 110375.

52. Liu, M., Zhang, J., Zhu, X., Shan, W., Li, L., Zhong, J., Zhang, Z. and Huang, Y., 2016. Efficient mucus permeation and tight junction opening by dissociable "mucus-inert" agent coated trimethyl chitosan nanoparticles for oral insulin delivery. $J$. Control. Release,222: 67-77.

53. Bari, H., 2010. A prolonged release parenteral drug delivery system: an overview. Int. J .Pharm. Sci. Rev. Res.,3(1):1-11.

54. Mitragotri, S., Burke, P.A. and Langer, R., 2014. Overcoming the challenges in administering biopharmaceuticals: formulation and delivery strategies. Nature reviews Drug discovery, 13(9): 655-672.

55. Nasongkla, N., Bey, E., Ren, J., Ai, H., Khemtong, C., Guthi, J.S., Chin, S.F., Sherry, A.D., Boothman, D.A. and Gao, J., 2006. Multifunctional polymeric micelles as cancer-targeted, mri-ultrasensitive drug delivery systems. Nano Lett.,6(11): 2427-2430.

56. Gaucher, G.V., Dufresne, M.H., Sant, V.P., Kang, N., Maysinger, D. and Leroux, J.C., 2005. Block copolymer micelles: Preparation, characterization and application in drug delivery. J. Control Release., 109(1): 169-188.

57. Ke, W., Yin, W., Zha, Z., Mukerabigwi, J.F., Chen, W., Wang, Y., He, C. and Ge, Z., 2018. A robust strategy for preparation of sequential stimuli-responsive block copolymer prodrugs via thiolactone chemistry to overcome multiple anticancer drug delivery barriers. Biomaterials, 154: 261-274.

58. Padmavathy, N., Das Ghosh, L., Meka, S.R.K. and Chatterjee, K., 2018. Synthesis of a Block Copolymer Exhibiting Cell-Responsive Phytochemical Release for Cancer Therapy. ACS applied materials \& interfaces, 10(26): 21816-21824.

59. Yang, C., Jeong, S., Ku, S., Lee, K. and Park, M.H., 2018. Use of gasotransmitters for the controlled release of polymer- based nitric oxide carriers in medical applications. Journal of controlled release, 279: 157-170.

60. Zheng, H., Li, X. and Jia, Q., 2018. Design of pH-responsive polymer monolith based on cyclodextrin vesicle for capture and release of myoglobin. ACS applied materials and interfaces, 10(6): 5909-5917.

61. Johnson, R.P. and Preman, N.K., 2019. Dual and multistimuliresponsive block copolymers for drug delivery applications. In Stimuli Responsive Polymeric Nanocarriers for Drug Delivery Applications, pp.249-267.

62. Lei, Z., Tang, Q., Ju, Y., Lin, Y., Bai, X., Luo, H. and Tong, Z., 2020. Block copolymer@ZIF-8 nanocomposites as a pHresponsive multi-steps release system for controlled drug delivery. Journal of Biomaterials Science, Polymer Edition: 117.

63. Shim, I.K., Yook, Y.J., Lee, S.Y., Lee, S.H., Park, K.D., Lee, M.C. and Lee, S.J., 2008. Healing of articular cartilage defects treated with a novel drug-releasing rod-type implant after microfracture surgery. Journal of controlled release, 129(3): 187-191.

64. Queiroz, M.L.B., Shanmugam, S., Santos, L.N.S., Campos, C.D.A., Santos, A.M., Batista, M.S., Araújo, A.A.D.S. and Serafini, M.R., 2020. Microneedles as an alternative technology for transdermal drug delivery systems: a patent review. Expert Opinion on Therapeutic Patents, (justaccepted).

65. Chen, F., Yan, Q., Yu, Y. and Wu, M.X., 2017. BCG vaccine powder-laden and dissolvable microneedle arrays for lesionfree vaccination. Journal of Controlled Release, 255: 36-44.

66. Yu, W., Jiang, G., Liu, D., Li, L., Chen, H., Liu, Y., Huang, Q., Tong, Z., Yao, J. and Kong, X., 2017. Fabrication of biodegradable composite microneedles based on calcium sulfate and gelatin for transdermal delivery of insulin. Materials Science and Engineering: C, 71: 725-734.

67. Zhao, X., Coulman, S.A., Hanna, S.J., Wong, F.S., Dayan, C.M. and Birchall, J.C., 2017. Formulation of hydrophobic peptides for skin delivery via coated microneedles. Journal of Controlled Release, 265: 2-13.

68. Yin, Z., Kuang, D., Wang, S., Zheng, Z., Yadavalli, V.K. and Lu, S., 2018. Swellable silk fibroin microneedles for transdermal drug delivery. International Journal of Biological Macromolecules, 106: 48-56.

69. Ali, R., Mehta, P., Arshad, M.S., Kucuk, I., Chang, M.W. and Ahmad, Z., 2020. Transdermal Microneedles-A Materials Perspective. AAPS Pharm. Sci. Tech., 21(1): p.12.

70. Kim, S., Yang, H., Eum, J., Ma, Y., Lahiji, S.F. and Jung, H., 2020. Implantable powder-carrying microneedles for transdermal delivery of high-dose insulin with enhanced activity. Biomaterials, 232: 119733.

71. Martinho, N., Damge, C. and Reis, C.P., 2011. Recent Advances in Drug Delivery Systems. $J$ Biomater Nanobiotechnol, 2(05): 510.

72. Jinno, Ji., Kamada, N., Miyake, M., Yamada, K., Mukai, T., Odomi, M., Toguchi, H., Liversidge, G.G., Higaki, K. and Kimura, T., 2006. Effect of particle size reduction on dissolution and oral absorption of a poorly water-soluble drug, cilostazol, in beagle dogs. J Control Release., 111(1): 56-64.

73. Graeser, K.A., Patterson, J.E., Zeitler, J.A. and Rades, T., 2010. The role of configurational entropy in amorphous systems. Pharmaceutics., 2(2): 224-244. 
74. Blagden, N., De Matas, M., Gavan, P.T. and York, P., 2007. Crystal engineering of active pharmaceutical ingredients to improve solubility and dissolution rates. Adv. Drug Deliv. Rev., 59(7): 617-630.

Table 1: Methods relating to incorporation of drug into protein-peptide drug delivery system

\begin{tabular}{|l|l|c|}
\hline Methods & \multicolumn{1}{|c|}{ Description } & Reference \\
\hline Emulsification & $\begin{array}{l}\text { Emulsification involves water soluble drugs being dissolved in aqueous layer and mixed } \\
\text { with organic solvent. In the presence of emulsifier in aqueous layer, w/o/w emulsion is } \\
\text { created. Organic solvent is removed under low pressure by evaporation and high } \\
\text { temperature. }\end{array}$ & $\begin{array}{l}\text { (Martinho et al., } \\
2011)\end{array}$ \\
\hline Jet milling & $\begin{array}{l}\text { Poorly soluble drugs like cilostazol dissolution rate was increased by jet milling, a } \\
\text { techniques that uses air compressed in high speed jet which helps in grinding of } \\
\text { materials to crash particles and to increase the bioavailability of cilostazol suspension } \\
\text { in matrix. }\end{array}$ & (Jinno et al., 2006) \\
\hline Ball milling & $\begin{array}{l}\text { A technique that uses steel balls as a grinder for grinding/blending of materials. It } \\
\text { reduces size of polymeric compounds and form amorphous powders of drugs in } \\
\text { polymeric compounds. A drug in an amorphous form play a major role in enhancing } \\
\text { their solubility rates because of their higher Gibbs energy even more than the } \\
\text { crystalline form. }\end{array}$ & (Graeseret \\
\hline Spray drying & $\begin{array}{l}\text { It is important to form microspheres and drug containing matrix which act as solution } \\
\text { and the drug is mainly expelled from the opening of fine tubes or nozzles as micro } \\
\text { droplets. The droplet size depends upon the properties of diameter of opening surface } \\
\text { to jet velocity. }\end{array}$ & (Martinho, 2011) \\
\hline Polymerization & $\begin{array}{l}\text { Hydrogels are polymerized by combination of monomer with drug and cross linking } \\
\text { agents. The photo-polymerized system used in intravascular delivery in inner blood } \\
\text { vessel surface. But gamma-radiation produces toxic effects for protein molecules which } \\
\text { is a drawback for protein and peptide drug delivery system. }\end{array}$ & (Martinho, 2011) \\
\hline Crystal engineering & $\begin{array}{l}\text { It helps in controlled crystallization utilizing non-covalent interactions which exists in } \\
\text { molecular/ionic components that help in normal design of solid-state drugs, indicating } \\
\text { electrical, magnetic, and optical properties. }\end{array}$ & (Blagden et al., \\
$2007)$
\end{tabular}

